\title{
Antibiotic Resistance Genes in the Human-Impacted Environment : A One Health Perspective
}

Tiedje, James M.

2019-06

Tiedje , J M , Wang , F , Manaia , C M , Virta , M , Sheng , H , Ma , L , Zhang , T \& Topp , E 2019 , ' Antibiotic Resistance Genes in the Human-Impacted Environment : A One Health Perspective ' , Pedosphere , vol. 29 , no. 3 , pp. 273-282 . https://doi.org/10.1016/S1002-0160(18)60062-1

http://hdl.handle.net/10138/329957

https://doi.org/10.1016/S1002-0160(18)60062-1

cc_by_nc_nd

acceptedVersion

Downloaded from Helda, University of Helsinki institutional repository.

This is an electronic reprint of the original article.

This reprint may differ from the original in pagination and typographic detail.

Please cite the original version. 


\section{Antibiotic Resistance Genes in the Human Impacted Environment: a One Health}

2 Perspective

3

4 James M. Tiedje ${ }^{\mathrm{a}, \mathrm{b}}$, Fang Wang ${ }^{\mathrm{a}, \mathrm{b}, \mathrm{c}^{*}}$, Célia M. Manaia ${ }^{\mathrm{d}}$, Marko Virta ${ }^{\mathrm{e}}$, Hongjie Sheng ${ }^{\mathrm{a}, \mathrm{b}}$, Liping Ma

$5 \quad$ f, Tong Zhang ${ }^{\mathrm{f}}$, Edward Topp ${ }^{\mathrm{g}}$

$6{ }^{a}$ Key Laboratory of Soil Environment and Pollution Remediation, Institute of Soil Science, Chinese

$7 \quad$ Academy of Sciences, Nanjing 210008, China

$8{ }^{b}$ Center for Microbial Ecology, Department of Plant, Soil and Microbial Sciences, Michigan State

$9 \quad$ University, East Lansing, Michigan 48824, United States

10

11

12

13

14

15

16

17

${ }^{c}$ University of Chinese Academy of Sciences, Beijing 100049, China

${ }^{d}$ Universidade Católica Portuguesa, CBQF - Centro de Biotecnologia e Química Fina - Laboratório Associado, Escola Superior de Biotecnologia, Rua Arquiteto Lobão Vital, 172, 4200-374 Porto,

Portugal

${ }^{e}$ Department of Microbiology, University of Helsinki, Viikinkaari 9, 00014 University of Helsinki,

Finland

${ }^{f}$ Environmental Biotechnology Lab, The University of Hong Kong, Hong Kong, China

${ }^{g}$ London Research and Development Centre, Agriculture and Agri-Food Canada, and University of Western Ontario, London, ON, Canada

*Corresponding author. E-mail: wangfang@issas.ac.cn 


\section{Abstract}

Antibiotic resistance and its environmental component is gaining more attention as part of combating the growing healthcare crisis. The One-Health framework, promulgated by many global health agencies, recognizes that antimicrobial resistance is a truly inter-domain problem in which human health, animal agriculture and the environment are the core and interrelated components. This prospectus presents the status and issues relevant to the environmental component of antibiotic resistance, namely the needs for advancing surveillance methodology: the environmental reservoirs and sources of resistance, namely urban wastewater treatment plants, aquaculture production systems, soil receiving manures and biosolids and the atmosphere which includes longer range dispersal. Much recent work has been done describing antibiotic resistance genes in various environments; now quantitative, mechanistic and hypothesis driven studies are needed to identify practices that reduce real risk and maintain effectiveness of our current antibiotics as long as possible. Advanced deployable detection methods for antibiotic resistance in diverse environmental samples are needed to provide the surveillance information to identify risk and define barriers that can reduce risk. Also needed are practices that reduce antibiotic use and thereby reduce selection for resistances, as well as practices that limit dispersal or destroy antibiotic resistant bacteria or their resistance genes that are feasible for these varied environmental domains.

Key words: Antibiotic Resistance, Transmission, Agriculture, One-Health 


\section{Introduction}

The overuse and misuse of antibiotics for human therapy and livestock production around the world over the past decades have increased antimicrobial resistance in diverse environments (Berendonk et al., 2015; Garbisu et al., 2018). Exposure to antibiotic resistant bacteria (ARB) and antibiotic resistance genes (ARGs) in the environment can increase the prevalence of resistance determinants in the human microbiome (Leonard et al., 2015). In December 2017, the United Nations Environment Programme identified environmental antibiotic resistance as the top of six emerging issues of concern (UNEP, 2017). Together with climate change, water stress and environmental degradation, widespread antibiotic resistance should be regarded as one of the global challenges humans face in this century.

ARGs have been widely identified in various environments, including wastewater and sludge (Manaia et al., 2018), livestock farms and soil (Zhu et al., 2013), river water and sediment (Muziasari et al., 2017), drinking water (Ma et al., 2017a), glacier environments (Segawa et al., 2013) and even the Antarctic (Wang et al., 2016). The use of antibiotics in therapy and livestock production has greatly promoted the development and spread of antibiotic resistance making impacted environments into large reservoirs of ARGs (Larsson et al., 2018; Manaia et al., 2018). Furthermore, the prevalence of mobile genetic elements, e.g. transposons, integrons and plasmids, could promote the horizontal gene transfer of ARGs to other bacteria including human pathogens, exacerbating the antimicrobial resistance issue (Gillings et al., 2015; Ma et al., 2017b).

Previously studies on antibiotic resistance mainly focused on clinical microorganisms to address the direct threat of emerging antibiotic resistant bacteria on public health. With the emergence of superbugs (multidrug resistant human pathogens) in medical treatment, both medical and public concern has increased. This has led to recognition that this is a problem that requires an interdisciplinary vision since it clearly involves not only human medicine but also agriculture and veterinary medicine as well as a range of environmental domains. The result has been formulation of the "One-Health" concept to engage scientists and practitioners across these disciplines to study the 
problem and its remedies in a cross-disciplinary manner. Antibiotic resistance has been described as the "quintessential" One-Health issue (Robinson et al., 2006). It involves antimicrobial resistance (AMR) in three main domains (Figure 1): Human health, animal agriculture and the environment. The United Nations through its agencies: the UNEP, the World Health Organization (WHO), the Food and Agriculture Organization (FAO), and the World Organisation for Animal Health (OIE) work jointly to promote collective action to minimize the emergence and spread of AMR. As illustrated in Figure 1, soil is a central component in One-Health since it harbors a large natural resistome but also receives $\mathrm{ARB}$ and $\mathrm{ARGs}$ from both human and animal wastes which can be returned to humans through vegetable and animal products, through surface, ground and reclaimed water, and via aerosols This is particularly important for soil science research because of: i) its central role as a reservoir, thus potential source for resistance traits, ii) the many routes of dissemination including to humans and iii) the large natural background of resistance which makes it more difficult to assess humanenhanced resistance and high risk AMR.

\section{Detection of antibiotic resistance genes in the environment}

One of the major needs to address the antibiotic resistance issue is improved AMR surveillance incorporating clinical, agricultural and environmental data at local, national and global levels (Hughes et al., 2016). This has been a challenge for the environmental domain since a legacy of methods tuned to the environment has not been established. In the last decade, molecular methods to quantify ARGs in the environment and their distribution and propagation in wastewater and sludge, aquaculture, soil and atmosphere have been developed or improved. These are primarily of three types: PCR based amplification of ARGs, hybridization of DNA to ARG gene fragments and searching metagenomic sequence data for ARGs. The former includes the polymerase chain reaction (PCR), quantitative realtime PCR (qPCR), DNA microarray and DNA hybridization. The traditional target sequence amplification-based methods, PCR and qPCR, have been widely applied to detect and quantify ARGs in diverse environmental samples because of their high sensitivity for ARGs detection under low 
abundance in natural environments. However, due to the limitations of primers available for ARGs amplification, PCR and qPCR approaches could only effectively detect well-studied ARGs. Besides, ARGs primers may cause biases and false negative/positive results, and only several ARGs could be detected in one set using traditional methods (Laht et al., 2014; Titilawo et al., 2015; Xiong et al., 2015). In recent years, improvements have provided high-throughput (highly parallel) qPCR for detection of hundreds of ARGs in one run (Looft et al., 2012). To further improve its efficiency and coverage, 294 primer sets for ARGs and some mobile genetic elements (MGEs) were developed (Zhu et al., 2013) and validated by sequencing its amplicons (Johnson et al., 2016). This was subsequently expanded to 384 primers (Wang et al., 2016). Recently, the results from over 500 diverse samples were evaluated, and together with updated reference data and a new primers design tool, EcoFunPrimer, Primer set 2.0 for highly parallel qPCR was tested and reported (Stedtfeld et al., 2018). The rapid development of high-throughput sequencing (HTS) technology in the past decade has enabled sequence-based metagenomic analysis to be widely applied in diverse ecological, medical, engineering and physical studies (Kircher and Kelso, 2010), including in assaying ARB and ARGs in environmental samples (Zeng et al., 2015; Ma et al., 2016). HTS technique can rapidly generate large amounts of sequence data at a relatively low cost (Kircher and Kelso, 2010). Metagenomic analysis is a culture-independent molecular approach, which uses the generated metagenomic sequences to search, annotate and predict targeted genes. For annotation and detection of ARGs in environmental samples, the generated metagenomic sequences are filtered for quality control and then compared against a reference ARG database that contains sequences of the known ARGs. With the increasing concerns of ARB and ARGs in both medical treatment and environmental monitoring, several ARG databases have been constructed to facilitate the ARGs annotation, including ARDB (Liu and Pop, 2009), CARD (Jia et al., 2017), ARG-ANNOT (Gupta et al., 2014) and ResFinder (Zankari et al., 2012). One structured database derived from combining ARBD and CARD was designed to search metagenomic data and classify the annotation results into 24 ARG types and 1208 subtypes (Yin et al., 2018). 
A variation of the above approach of searching for ARGs in metagenomic data is to first

assemble the short-read ARG fragments to gain more reliability in gene identification. This can be done by gene-targeted assembly tools such as Xander (Wang et al., 2015) or Mega GTA (Li et al., 2017). One study reports this result in soils for 35 ARGs (Dunivin and Shade, 2018).

Challenges remain on improving the detection limit and identifying untargeted ARGs, which can be potentially-emerging, problematic ARGs. All of the above molecular methods are based on sequence information from known ARGs. None of these methods can detect cryptic ARGs. Further, many ARG sequences may be part of the natural resistome, code for functions that by themselves do not confer resistance, or may not be expressed.

The comparison of antimicrobial resistance among different environmental niches with culturebased clinical (pathogen) resistance is necessary for improving our knowledge on the evolution, spread and risk of ARGs in the environment. However, standard methods and criteria specifically designed for meeting this need in environmental samples is lacking. One challenge for use of culturebased methods for environmental samples is that $>99 \%$ of environmental microorganisms are not cultivable, and another is that pathogen recovery can be inefficient due to their injury or stress from being in the environment. Therefore, improvement of methods through combining molecular methods, perhaps informed by DNA sequence or biochemical markers from clinical or culture-based studies, with high-throughput sequencing will provide a comprehensive overview of antimicrobial resistance as well as specific areas of higher risk in diverse environmental samples. One example of that kind of method is epicPCR which can link the host and ARG without culturing in high throughput method (Hultman et al., 2018). Future attention should also be paid to tracking antimicrobial resistance from pollution sources versus natural environments to human-related environments, as important guidance for management of antimicrobial resistance risk.

\section{Antibiotic resistance genes in wastewater and sludge}

The major environmental sources of AMR, and especially those that are clinically relevant and 
have the potential to reach humans are from i) urban wastewater treatment plants, ii) use in aquaculture, iii) use in animal agricultural for growth promotion and therapeutic use. Other sources, not discussed here, but should not be neglected, are antibiotic production and formulation factories and used as a 'pesticide' on some food crops. Furthermore, the use of antibiotics for treatment of companion animals, and transmission of ARB by wildlife, including birds, and the irrigation of crops with reclaimed wastewater, are sources to also be recognized (Fig. 1).

Domestic wastewater treatment plants, also known as urban wastewater treatment plants (UWTPs), also receive ARGS and ARBs from domestic and clinical sources but cannot remove them nor most antibiotics by the most commonly used technologies applied in the treatment of domestic effluents. Therefore, in spite of reducing the abundance of bacteria in the effluents, wastewater treatment, fulfilling the legal recommendations (e.g. Directive 91/271/EEC on Urban Waste Water Treatment and following amendments in the European Union), leads to the continuous release of ARB and ARGs into the environment (Vaz-Moreira et al., 2014; Manaia et al., 2016). Unfortunately, the risks posed by these high loads of ARBs and ARGs are still poorly understood (Czekalski et al., 2014; Li et al., 2016; Osinska et al., 2016; Proia et al., 2016; Li et al., 2018).

The recognition of antibiotic resistance in waste water effluents has stimulated the study of occurrence and potential control of antibiotic resistance in UWTPs. Most abundant classes of ARGs were found in raw influents and final effluents, accumulated in activated sludge during secondary/biological treatment or reaching the UWTP surrounding environment (Karkman et al., 2018). Not surprisingly, these genes are frequently detected in or statistically associated to bacterial genera and species known to be hosted transiently or permanently by humans (Narciso-da-Rocha et al., 2014; Narciso-da-Rocha et al., 2018). In addition, the presence of mobile genetic elements (MGEs), involved in horizontal gene transfer (HGT), particularly, plasmids and phages, as well as, genetic recombination elements in the wastewater metagenome, highlights the potential for the propagation of ARGs, within and across different environmental compartments (Dolejska and Papagiannitsis, 2018). Of note, is the fact that this core wastewater resistome (totality of resistance 
genes) and mobilome (the totality of elements involved in HGT and genetic recombination) is continuously evolving by the rapid incorporation of genes emerging in clinical settings (Karkman et al., 2018).

Advanced treatment options, such as chlorination, ozonation or UV, or combined disinfection approaches may reduce the environmental emission of ARGs from UWTPs (Dodd, 2012; Giannakis et al., 2018). The reactivation and regrowth of bacteria after disinfection, particularly of fast growing bacteria, also may need attention in order to minimize the proliferation of ARB or ARGs after disinfection and during water storage (Becerra-Castro et al., 2016; Sousa et al., 2017).

\section{Antibiotic resistance genes in aquaculture}

As a global source of fish and shellfish, the significance of aquaculture has increased remarkably in the last 50 years (Watts et al., 2017), with the aquaculture production already surpasses the catch of the wild growing aquatic species. The term aquaculture can refer to a large spectrum of activities. The extensive aquaculture relies on native species which are helped by removing predators and competing species whereas in the intensive aquaculture the cultured species are more isolated from the environment and the food is supplied externally. On the other hand, the term covers everything between farming salmon offshore in the cold Atlantic water to tropical integrated aquaculture where excess animal feed and livestock manure are nutrients for the aquaculture. Therefore, it is not too surprising that there is no single picture of the antibiotic use in aquaculture.

Use of antibiotics in aquaculture is strictly regulated in Europe, Japan and North America. In those regions, the use of antibiotics is limited to therapeutic applications where only a limited number of antibiotics are approved. As an example, only five different antibiotics are authorized for use in aquaculture in the UK, compared to 13 different ones in China (Liu et al., 2017). Some forms of aquaculture use antibiotics in a sustainable way, with the salmon production in Norway as probably the best example. Between 1987 and 2013 the antibiotic use in that production system was reduced by $99 \%$ concurrent with a 20 -fold increase in the tonnage produced (Norwegian Ministry of Health 
and Care Services 2015). The main factors behind such development are implementation of strict use of vaccines and hygienic requirements, which partly resulted from active scientific research in this field. There are obviously other than scientific and technological challenges involved since the uses of antibiotics in aquaculture varies tremendously even with the same fish species. The reason behind that difference is still not clear but it probably includes not only lack of vaccination, but also high fish density and sub-optimal fishing practices which includes at least underdeveloped hygiene and feeding with unknown components that might contain antibiotics or other agents causing the selection pressure for antibiotic resistance. Additionally, aquaculture systems integrating the wastes from livestock production are effective for nutrient cycling, but may have potential problems of disseminating antibiotic resistance (Cabello et al., 2016).

\section{Antibiotic resistance genes in soil}

Of all the environments impacted by humans, soil undoubtedly contains the richest and most diverse populations of microorganisms (Thompson et al., 2017) and DNA sequence (Rodriguez-R et al., 2018). Soil bacteria carry antibiotic resistance genes that are also found in human clinical pathogens, and novel ones that are for the first time being discovered (Lau et al., 2017). A key human activity of concern with respect to antimicrobial resistance that impacts the soil environment is the land application of fecal material, largely through agricultural practice (O'Connor et al., 2005; Larney, 2011; Wang et al., 2018). Organic amendments of animal (manures) or human (i.e. biosolids) origin are widely used as a valued source of nutrients and for crop production and organic matter for soil improvement. The use of antibiotics for prophylaxis or therapy in commercial food animal production will select for and enrich ARB in the digestive tract, and these bacteria will end up in the manure (Zhu et al., 2013). Manure will also contain residues of antibiotics that have been excreted intact in the urine or feces (Pope et al., 2009). The microbial and chemical composition of raw manures will vary with the commodity (i.e. poultry, swine, beef, dairy) and the medications used. Likewise, biosolids contain residues of antibiotics and other potential co-selective agents such as biocides 
(Sabourin et al., 2012). Treatment practices that reduce the abundance of ARB and destroy antibiotic residues will reduce soil loading rates of these contaminants and are therefore desirable (Lau et al., 2017; Tien et al., 2017).

Another increasingly important practice of concern with respect to potentiating antibiotic resistance in soils is irrigation with reclaimed wastewater (Christou et al., 2017). Irrigation with nutrient-rich raw or poorly treated sewage is sometimes practiced in lower income countries (Thebo et al., 2017). Turfgrass in green spaces in urban or peri-urban settings may also be irrigated with reclaimed wastewater (Wang et al., 2014). Depending on the degree of treatment, reclaimed wastewater will contain ARB and residues of pharmaceuticals including antibiotics (Pan and Chu, 2018).

Soil contamination with metals and organic chemicals other than antibiotics that co-select for antibiotic resistance are of concern. Contamination of soil with copper and zinc from mining activities or the application of manure from animals that consume feed supplemented with the metals can coselect for genetic elements that confer resistance to both metals and antibiotics (Poole, 2017). Copper is also commonly spread on fruits and vegetables as a pesticide against bacterial and fungal plant pathogens. Interestingly, some herbicides decrease the sensitivity of Gram negative bacteria to some antibiotics, possibly through upregulating efflux (Kurenbach et al., 2015). Likewise, there is a concern that the widespread use of fungicides in crop production will select for resistance that will end up eroding the efficacy of fungicides used to treat human fungal or yeast infections (Jensen, 2016). Fungicides are also entrained into soil through the application of biosolids (Chen et al., 2013).

Given the chemical, biological and physical complexity of manures and biosolids it is extremely difficult to determine which specific agent or classes of agents interact with soil microorganisms to promote antibiotic resistance. Laboratory evidence suggests that in the presence of antibiotics, viruses (bacteriophage) disseminate antibiotic resistance genes more rapidly in manured soil than in the absence of antibiotics (Ross and Topp, 2015).

Soil can also affect the growth inhibition and selection pressure of antibiotics on the microbes 
by sorption of the antibiotic reducing their bioavailability, which is determined by the chemical properties of the antibiotic and the soil matrix. In some cases soil reduces the growth inhibition of pathogens by certain antibiotics and for other antibiotics it does not (Chander et al., 2005; Subbiah et al., 2011). More recent mechanistic work shows that soils and their associated mineral and organic constituents affects the bioavailability of tetracycline as measured by a bioreporter linked to ARG expression (Chen et al., 2017). Antibiotic residues that are sorbed on clay mineral surfaces turned on the bioreporter suggesting that they would be able to provide selective pressure for antimicrobial resistance (Zhang et al., 2018).

\section{Antibiotic resistance genes in the atmosphere}

Due to its emerging threat to public health, the existence of ARGs in the atmosphere, especially urban air, has given rise to more attention. Comprehensive knowledge of the types and abundance of ARGs in the air and whether they are associated with potential pathogens can provide new guidance for assessment of air quality.

The relative abundance profiles of ARGs are spatially and temporally distributed in ambient air of various cities. On heavy air pollution days, the increase of airborne particles is conductive to suspending of microbes by providing more adhesion sites (Hu et al., 2018). There was a higher richness with 64 ARG types in bacterial biota in Beijing smog than in other environments, such as pharmaceutically polluted environments, wastewater/sludge, animals and other terrestrial sources (Pal et al., 2016). These results indicate that airborne transmission plays a crucial role in the global environmental distribution and exposure of antimicrobial resistance compared with other routes. Evidence support that such a risk is attributed to diverse antibiotic usage in different cities. In rural settings, airborne particulate matter promoted the transmission of microbial biota harboring antimicrobial resistance genes downwind of cattle feedlots (McEachran et al., 2015). The dispersal patterns of particulate matter-borne ARGs were also impacted by physicochemical factors, meteorological parameters and bacterial communities (Hu et al., 2018). Pathogens in clinical ambient 
air may be resistant to multiple drugs, threating inhabitants as well as people outside hospitals via airborne spread (Huang et al., 2012).

Unfortunately, knowledge on airborne ARGs in geographically, culturally, and economically different areas on a global scale is lacking. Their health impact is still unknown. On the other hand, considerable attention is paid on particulate matter mass concentration, e.g. PM 2.5, while biological parameters such as ARGs or ARB are yet to be adequately evaluated (Li et al., 2018).

\section{Transmission of antibiotic resistance genes in the environment}

Two major factors determine the fate of ARGs in the environment: dispersal mechanisms and selection. The dissemination of resistance genes is attributed to physical and biological forces throughout various environments. Physical forces drive the dispersal of ARGs, such as wind and waters, including erosion and leaching, but so do wild animals, e.g. birds, deer, raccoons. Major routes of human exposures are from contaminated foods, e.g. vegetables with exposure to manures or reclaimed wastewater, or meats contaminated with fecal waste from slaughter (Fig. 1). Less likely sources are from drinking water, which is highly source dependent, and air. Pets can also be a source and a recipient from their owner, and thereby cycle the AMR (Fig. 1). Proximity to human activities provides an enriched source of ARGs for potential dispersal. For example, human proximity is closely related to the antibiotic resistance profiles of the gut bacteria of wild mammals, whose habitats can be affected by antibiotics (Allen et al., 2010).

The selection pressure exerted on environmental bacteria can be of two types: selection for the microbes that are carrying ARGs that is independent of the resistance trait, e.g. for particular carbon sources, faster growth rate, resistances to stressors like $\mathrm{pH}$; and selection for ARG trait which can be the antibiotic itself or co-selection for resistances that are genetically linked to another (or multiple) ARGs. The type of selective agent (chemical speciation and concentrations), co-exposure to other selective agents (exposure period) and under what environmental conditions are essential for differential bacterial growth (Baquero et al., 2009; Larsson et al., 2018). An overview of the 
characteristics, variability and abundance of ARGs and mobile genetic elements, and their transmission efficiencies in various circumstances is necessary to better differentiate ambient from anthropogenic sources of antibiotics and ARGs in the environment (Hunter et al., 2008; Zhu et al., 2017; Larsson et al., 2018). Such transfer and selection patterns of genes and bacteria are important guides to distinguish the most urgent exposure and risk reduction practices.

\section{Conclusions and One Health perspective}

Humans profoundly impact the environment, in particular through agricultural practice. There is a need to better understand what specific practices represent what risk with respect to AMR in soil, water, air, and human health. This needs to be done considering the realities of how agriculture and aquaculture are undertaken in high, middle and lower-income settings. There is also a need to better understand how the fate and impacts of microbial and chemical contaminants that reach soil and water vary with climate, particularly extremes of temperature and rainfall.

Importantly, changes in food animal production practices that reduce antimicrobial use will reduce selection for and transmission of antibiotic-resistant bacteria. One practice that has long been questioned is the use of sub-therapeutic doses for growth promotion in animal production. It has been widely practiced because it does speed time to market and hence lower cost of food, but it has been targeted as a non-essential practice that promotes AMR. Progress is being made though as this practice has been banned in the EU since January 2006 and in the U.S. since January 2017. This could only be accomplished in concert with changes in production systems that minimize disease and maintain farmer profitability. Currently vaccination is an economically viable practice especially with high value species (e.g. salmon) in some developed countries. Development of alternatives to antibiotics, like vaccines, is needed but they must be cost competitive to have an impact on antibiotic use. This is an important area for research.

The relevance of ARB and ARGs as environmental contaminants is now accepted but there still exist some key priority issues. There is currently limited evidence that permit an objective and 
quantitative assessment of the human health risks posed by the occurrence of ARB in the environment. For this reason, it is difficult to define threshold values for the maximum admissible levels of ARB and ARGs in treated wastewater, in sludge and manure to be used in agriculture. Increasing water scarcity and soil degradation will drive increased need for water reuse, and beneficial reuse of municipal sludges and manures, likely increasing inputs of ARGs and ARBs into soil. The movement of people and food between higher and lower income countries will contribute to the global transmission of resistance from regions with poor sanitary conditions. Improving water sanitation and hygiene in lower income countries should be a global priority. Overall, adequate risk assessment frameworks, policy development and implementation, definition of circular economy good practices and ensuring adequate sanitation are priorities to reduce antibiotic resistance burden and global transmission (Pruden et al., 2013).

The One Health framework was developed in recognition of the inter-domain system in which antibiotic resistance resides and circulates (Fig. 1). Among the three domains, human health is the spotlight, due to multidrug-resistance genes have been prevalent in several important pathogens. To achieve the goal of One Health, veterinarians, physicians, food safety professionals, wastewater treatment plant operators, environmental experts and regulators are obliged to work together. At a policy level, all countries were asked to formulate a "National Action Plan" to combat antimicrobial resistant appropriate for their country (WHO, 2017). Many have done so, but the challenge is now to effectively implement and monitor these plans, and to validate the efficacy of practices intended to reduce the development and spread of AMR. Thus the overriding importance of undertaking surveillance is across the One Health Framework.

\section{Acknowledgments}

F. Wang's research is funded by the National Natural Science Foundation of China (21677149), the Outstanding Youth Fund of Natural Science Foundation of Jiangsu, China (BK20150050), the Innovative Project of the Chinese Academy of Sciences (ISSASIP1616). J. M. Tiedje's research is 
351 funded by, and the Center for Health Impacts of Agriculture (CHIA) of Michigan State University. E.

352 Topp's research is funded by Agriculture and Agri-Food Canada, the Canadian Genomics Research 353 Development Initiative (GRDI-AMR), and the Canadian Institute for Health Research (CIHR) 354 through the Joint Programming Initiative on Antimicrobial resistance (JPIAMR). C. M. Manaia 355 acknowledges the National Funds from FCT - Fundação para a Ciência e a Tecnologia through project 356 UID/Multi/50016/2013. M. Virta's research is funded by Academy of Finland and JPI-Water.

References

Allen H K, Donato J, Wang H H, Cloud-Hansen K A, Davies J, Handelsman J. 2010. Call of the wild: Antibiotic resistance genes in natural environments. Nat Rev Microbiol. 8: 251-259.

Baquero F, Alvarez-Ortega C, Martinez J L. 2009. Ecology and evolution of antibiotic resistance. Environ Microbiol Rep. 1: 469-476.

Becerra-Castro C, Macedo G, Silva A M T, Manaia C M, Nunes O C. 2016. Proteobacteria become predominant during regrowth after water disinfection. Sci Total Environ. 573: 313-323.

Berendonk T U, Manaia C M, Merlin C, Fatta-Kassinos D, Cytryn E, Walsh F, Burgmann H, Sorum H, Norstrom M, Pons M N, Kreuzinger N, Huovinen P, Stefani S, Schwartz T, Kisand V, Baquero F, Martinez J L. 2015. Tackling antibiotic resistance: The environmental framework. Nat Rev Microbiol. 13: 310-317.

Cabello F C, Godfrey H P, Buschmann A H, Dölz H J. 2016. Aquaculture as yet another environmental gateway to the development and globalisation of antimicrobial resistance. Lancet Infec Dis. 16: e127-e133.

Chander Y, Kumar K, Goyal S M, Gupta S C. 2005. Antibacterial activity of soil-bound antibiotics. J Environ Qual. 34: 1952-1957.

Chen Z F, Ying G G, Ma Y B, Lai H J, Chen F, Pan C G. 2013. Typical azole biocides in biosolidamended soils and plants following biosolid applications. J Agr Food Chem. 61: 6198-6206.

Chen Z, Zhang W, Wang G, Zhang Y, Gao Y, Boyd S A, Teppen B J, Tiedje J M, Zhu D, Li H. 2017. 
Bioavailability of soil-sorbed tetracycline to escherichia coli under unsaturated conditions. Environ Sci Technol. 51: 6165-6173.

Christou A, Agüera A, Bayona J M, Cytryn E, Fotopoulos V, Lambropoulou D, Manaia C M, Michael C, Revitt M, Schröder P, Fatta-Kassinos D. 2017. The potential implications of reclaimed wastewater reuse for irrigation on the agricultural environment: The knowns and unknowns of the fate of antibiotics and antibiotic resistant bacteria and resistance genes - a review. Water Res. 123: 448-467.

Czekalski N, Gascón Díez E, Bürgmann H. 2014. Wastewater as a point source of antibioticresistance genes in the sediment of a freshwater lake. ISME J. 8: 1381-1390.

Dodd M C. 2012. Potential impacts of disinfection processes on elimination and deactivation of antibiotic resistance genes during water and wastewater treatment. J Environ Monitor. 14: $1754-1771$.

Dolejska M, Papagiannitsis C C. 2018. Plasmid-mediated resistance is going wild. Plasmid. 99: 99111.

Dunivin T K, Shade A. 2018. Community structure explains antibiotic resistance gene dynamics over a temperature gradient in soil. FEMS Microbiol Ecol. 94: 1-9.

Garbisu C, Garaiyurrebaso O, Lanzen A, Alvarez-Rodriguez I, Arana L, Blanco F, Smalla K, Grohmann E, Alkorta I. 2018. Mobile genetic elements and antibiotic resistance in mine soil amended with organic wastes. Sci Total Environ. 621: 725-733.

Giannakis S, Le T M, Entenza J M, Pulgarin C. 2018. Solar photo-fenton disinfection of 11 antibioticresistant bacteria (ARB) and elimination of representative ar genes. Evidence that antibiotic resistance does not imply resistance to oxidative treatment. Water Res. 143: 334-345.

Gillings M R, Gaze W H, Pruden A, Smalla K, Tiedje J M, Zhu Y G. 2015. Using the class 1 integronintegrase gene as a proxy for anthropogenic pollution. ISME J. 9: 1269-1279.

Gupta S K, Padmanabhan B R, Diene S M, Lopez-Rojas R, Kempf M, Landraud L, Rolain J M. 2014. Arg-annot, a new bioinformatic tool to discover antibiotic resistance genes in bacterial 
genomes. Antimicrob Agents Ch. 58: 212-220.

Hu J, Zhao F, Zhang X-X, Li K, Li C, Ye L, Li M. 2018. Metagenomic profiling of args in airborne particulate matters during a severe smog event. Sci Total Environ. 615: 1332-1340.

Huang X Z, Frye J G, Chahine M A, Glenn L M, Ake J A, Su W, Nikolich M P, Lesho E P. 2012. Characteristics of plasmids in multi-drug-resistant enterobacteriaceae isolated during prospective surveillance of a newly opened hospital in iraq. Plos One. 7: 1-8.

Hughes M J, Tiedje M J, Bell B, Call D, Cassell G, Crawford C, Granger L, Miller A. 2016. AMR Steering Commitee Meeting Summary, American Society for Microbiology, Washington DC.

Hultman J, Tamminen, M, Pärnänen, K, Cairns, J, Karkman, A,Virta, M. 2018. Host range of antibiotic resistance genes in wastewater treatment plant influent and effluent. FEMS Microb Ecol. 94;: fiy038.

Hunter P R, Wilkinson D C, Catling L A, Barker G C. 2008. Meta-analysis of experimental data concerning antimicrobial resistance gene transfer rates during conjugation. Appl Environ Microb. 74: 6085-6090.

Jensen R H. 2016. Resistance in human pathogenic yeasts and filamentous fungi: Prevalence, underlying molecular mechanisms and link to the use of antifungals in humans and the environment. Dan Med J. 63: 1-11.

Jia B F, Raphenya A R, Alcock B, Waglechner N, Guo P Y, Tsang K K, Lago B A, Dave B M, Pereira S, Sharma A N, Doshi S, Courtot M, Lo R, Williams L E, Frye J G, Elsayegh T, Sardar D, Westman E L, Pawlowski A C, Johnson T A, Brinkman F S L, Wright G D, McArthur A G. 2017. Card 2017: Expansion and model-centric curation of the comprehensive antibiotic resistance database. Nucleic Acids Res. 45: D566-D573.

Johnson T A, Stedtfeld R D, Wang Q, Cole J R, Hashsham S A, Looft T, Zhu Y-G, Tiedje J M. 2016. Clusters of antibiotic resistance genes enriched together stay together in swine agriculture. Mbio. 7: e02214-e02215.

Karkman A, Do T T, Walsh F, Virta M P J. 2018. Antibiotic-resistance genes in waste water. Trends 
Kircher M, Kelso J. 2010. High-throughput DNA sequencing - concepts and limitations. Bioessays. 32: 524-536.

Kurenbach B, Marjoshi D, Amabile-Cuevas C F, Ferguson G C, Godsoe W, Gibson P, Heinemann J A. 2015. Sublethal exposure to commercial formulations of the herbicides dicamba, 2,4dichlorophenoxyacetic acid, and glyphosate cause changes in antibiotic susceptibility in escherichia coli and salmonella enterica serovar typhimurium. Mbio. 6: 1-9.

Laht M, Karkman A, Voolaid V, Ritz C, Tenson T, Virta M, Kisand V. 2014. Abundances of tetracycline, sulphonamide and beta-lactam antibiotic resistance genes in conventional wastewater treatment plants (wwtps) with different waste load. PLoS One. 9: 1-8.

Larney F J, X. Hao, and E. Topp. 2011 Soil management: Building a sustainable base for agriculture American Society for Agronomy, Madison WI.

Larsson D G J, Andremont A, Bengtsson-Palme J, Brandt K K, Husman A M d R, Fagerstedt P, Fick J, Flach C F, Gaze W H, Kuroda M, Kvint K, Laxminarayan R, Manaia C M, Nielsen K M, Plant L, Ploy M C, Segovia C, Simonet P, Smalla K, Snape J, Topp E, van Hengel A J, VernerJeffreys D W, Virta M P J, Wellington E M, Wernersson A-S. 2018. Critical knowledge gaps and research needs related to the environmental dimensions of antibiotic resistance. Environ Int. 117: 132-138.

Lau C H F, Li B, Zhang T, Tien Y C, Scott A, Murray R, Sabourin L, Lapen D R, Duenk P, Topp E. 2017. Impact of pre-application treatment on municipal sludge composition, soil dynamics of antibiotic resistance genes, and abundance of antibiotic-resistance genes on vegetables at harvest. Sci Total Environ. 587: 214-222.

Lau C H F, Van Engelen K, Gordon S, Renaud J, Topp E. 2017. Novel antibiotic resistance determinants from agricultural soil exposed to antibiotics widely used in human medicine and animal farming. Appl Environ Microbiol. 83: 1-18.

Leonard A F C, Zhang L, Balfour A, Garside R, Gaze W H. 2015. Human recreational exposure to 
antibiotic resistant bacteria in coastal bathing waters. Environ Int. 82: 92-100.

Li A, Chen L, Zhang Y, Tao Y, Xie H, Li S, Sun W, Pan J, He Z, Mai C, Fan Y, Xian H, Zhang Z, Wen D. 2018. Occurrence and distribution of antibiotic resistance genes in the sediments of drinking water sources, urban rivers, and coastal areas in zhuhai, china. Environ Sci Pollut R. 25: $26209-26217$.

Li C, Lu J, Liu J, Zhang G, Tong Y, Ma N. 2016. Exploring the correlations between antibiotics and antibiotic resistance genes in the wastewater treatment plants of hospitals in Xinjiang, China. Enviro Sci Pollut R. 23: 15111-15121.

Li D, Huang Y, Leung C M, Luo R, Ting H F, Lam T W. 2017. Megagta: A sensitive and accurate metagenomic gene-targeted assembler using iterative de bruijn graphs. BMC Bioinformatics. 18: $408-417$.

Li L G, Yin X, Zhang T. 2018. Tracking antibiotic resistance gene pollution from different sources using machine-learning classification. Mbio. 6: 93-93.

Liu B, Pop M. 2009. Ardb-antibiotic resistance genes database. Nucleic Acids Res. 37: D443-D447.

Liu X, Steele J C, Meng X Z. 2017. Usage, residue, and human health risk of antibiotics in Chinese aquaculture: A review. Environ Pollut. 223: 161-169.

Looft T, T. A. Johnson, H.K. Allen, D.O. Bayles, D.P. Alt, R.D. Stedtfeld, W.J. Sul, T.M. Stedtfeld, B. Chai B, J. R. Cole, S.A. Hashsham, J.M.Tiedje and T.B. Stanton. 2012. In-feed antibiotic effects on the swine intestinal microbiome. P Natl Acad Sci USA. 109(5): 1691-1696.

Ma L P, Li A D, Yin X L, Zhang T. 2017b. The prevalence of integrons as the carrier of antibiotic resistance genes in natural and man-made environments. Environ Sci Technol. 51: 5721-5728.

Ma L P, Li B, Jiang X T, Wang Y L, Xia Y, Li A D, Zhang T. 2017a. Catalogue of antibiotic resistome and host-tracking in drinking water deciphered by a large scale survey. Mbio. 5: 154-166.

Ma L P, Xia Y, Li B, Yang Y, Li L G, Tiedje J M, Zhang T. 2016. Metagenomic assembly reveals hosts of antibiotic resistance genes and the shared resistome in pig, chicken, and human feces. Environ Sci Technol. 50: 420-427. 
Manaia C M, Macedo G, Fatta-Kassinos D, Nunes O C. 2016. Antibiotic resistance in urban aquatic environments: Can it be controlled? Appl Microbiol and Biot. 100: 1543-1557.

Manaia C M, Rocha J, Scaccia N, Marano R, Radu E, Biancullo F, Cerqueira F, Fortunato G, Iakovides I C, Zammit I, Kampouris I, Vaz-Moreira I, Nunes O C. 2018. Antibiotic resistance in wastewater treatment plants: Tackling the black box. Environ Int. 115: 312-324.

McEachran A D, Blackwell B R, Hanson J D, Wooten K J, Mayer G D, Cox S B, Smith P N. 2015. Antibiotics, bacteria, and antibiotic resistance genes: Aerial transport from cattle feed yards via particulate matter. Environ Health Persp. 123: 337-343.

Muziasari W I, Pitkanen L K, Sorum H, Stedtfeld R D, Tiedje J M, Virta M. 2017. The resistome of farmed fish feces contributes to the enrichment of antibiotic resistance genes in sediments below baltic sea fish farms. Front Microbiol. 8: 1-10.

Narciso-da-Rocha C, Rocha J, Vaz-Moreira I, Lira F, Tamames J, Henriques I, Martinez J L, Manaia C M. 2018. Bacterial lineages putatively associated with the dissemination of antibiotic resistance genes in a full-scale urban wastewater treatment plant. Environ Int. 118: 179-188.

Narciso-da-Rocha C, Varela A, Schwartz T, Nunes O, Manaia C. 2014. Blatem and vana as indicator genes of antibiotic resistance contamination in a hospital-urban wastewater treatment plant system. J Glob Antimicrob Re. 2:309-315.

O'Connor G A, Elliott H A, Basta N T, Bastian R K, Pierzynski G M, Sims R C, Smith J E. 2005. Sustainable land application: An overview. J Environ Qual. 34: 7-17.

Osinska A, Harnisz M, Korzeniewska E. 2016. Prevalence of plasmid-mediated multidrug resistance determinants in fluoroquinolone-resistant bacteria isolated from sewage and surface water. Environ Sci Pollut R. 23: 10818-10831.

Pal C, Bengtsson-Palme J, Kristiansson E, Larsson D G J. 2016. The structure and diversity of human, animal and environmental resistomes. Mbio. 4: 54-69.

Pan M, Chu L M. 2018. Occurrence of antibiotics and antibiotic resistance genes in soils from wastewater irrigation areas in the pearl river delta region, southern china. Sci Total Environ. 
Poole K. 2017. At the nexus of antibiotics and metals: The impact of cu and $\mathrm{zn}$ on antibiotic activity and resistance. Trends Microbiol. 25: 820-832.

Pope L, Boxall A B A, Corsing C, Halling-Sorensen B, Tait A, Topp E. 2009. Veterinary medicines in the environment. SETAC, Pensacola, FL.

Proia L, von Schiller D, Sànchez-Melsió A, Sabater S, Borrego C M, Rodríguez-Mozaz S, Balcázar J L. 2016. Occurrence and persistence of antibiotic resistance genes in river biofilms after wastewater inputs in small rivers. Environ Pollut. 210: 121-128.

Pruden A, Larsson D G J, Amézquita A, Collignon P, Brandt Kristian K, Graham David W, Lazorchak James M, Suzuki S, Silley P, Snape Jason R, Topp E, Zhang T, Zhu Y G. 2013. Management options for reducing the release of antibiotics and antibiotic resistance genes to the environment. Environmental Health Perspectives. 121: 878-885.

Robinson D A, Sutcliffe J A, Tewodros W, Manoharan A, Bessen D E. 2006. Evolution and global dissemination of macrolide-resistant group a streptococci. Antimicrob Agents Ch. 50: 29032911.

Rodriguez-R L M, Gunturu S, Tiedje J M, Cole J R, Konstantinidis K T. 2018. Nonpareil 3: Fast estimation of metagenomic coverage and sequence diversity. Msystems. 3: 1-9.

Ross J, Topp E. 2015. Abundance of antibiotic resistance genes in bacteriophage following soil fertilization with dairy manure or municipal biosolids, and evidence for potential transduction. Appl Environ Microbiol. 81: 7905-7913.

Sabourin L, Duenk P, Bonte-Gelok S, Payne M, Lapen D R, Topp E. 2012. Uptake of pharmaceuticals, hormones and parabens into vegetables grown in soil fertilized with municipal biosolids. Sci Total Environ. 431: 233-236.

Segawa T, Takeuchi N, Rivera A, Yamada A, Yoshimura Y, Barcaza G, Shinbori K, Motoyama H, Kohshima S, Ushida K. 2013. Distribution of antibiotic resistance genes in glacier environments. Env Microbiol Rep. 5: 127-134. 
Sousa J M, Macedo G, Pedrosa M, Becerra-Castro C, Castro-Silva S, Pereira M F R, Silva A M T, Nunes O C, Manaia C M. 2017. Ozonation and uv254nm radiation for the removal of microorganisms and antibiotic resistance genes from urban wastewater. J Hazard Mater. 323: 434-441.

Stedtfeld R D, Guo X, Stedtfeld T M, Sheng H, Williams M R, Hauschild K, Gunturu S, Tift L, Wang F, Howe A, Chai B, Yin D, Cole J R, Tiedje J M, Hashsham S A. 2018. Primer set 2.0 for highly parallel qpcr array targeting antibiotic resistance genes and mobile genetic elements. FEMS Microbiol Ecol. 94: 1-9.

Subbiah M, Mitchell S M, Ullman J L, Call D R. 2011. Beta-lactams and florfenicol antibiotics remain bioactive in soils while ciprofloxacin, neomycin, and tetracycline are neutralized. Appl Environ Microbiol. 77: 7255-7260.

Thebo A L, Drechsel P, Lambin E F, Nelson K L. 2017. A global, spatially-explicit assessment of irrigated croplands influenced by urban wastewater flows. Environ Res Lett. 12: 1-12.

Thompson L R, Sanders J G, McDonald D, Amir A, Ladau J, Locey K J, Prill R J, Tripathi A, Gibbons S M, Ackermann G, Navas-Molina J A, Janssen S, Kopylova E, Vázquez-Baeza Y, González A, Morton J T, Mirarab S, Zech Xu Z, Jiang L, Haroon M F, Kanbar J, Zhu Q, Jin Song S, Kosciolek T, Bokulich N A, Lefler J, Brislawn C J, Humphrey G, Owens S M, HamptonMarcell J, Berg-Lyons D, McKenzie V, Fierer N, Fuhrman J A, Clauset A, Stevens R L, Shade A, Pollard K S, Goodwin K D, Jansson J K, Gilbert J A, Knight R, The Earth Microbiome Project C. 2017. A communal catalogue reveals earth's multiscale microbial diversity. Nature. 551: $457-477$.

Tien Y C, Li B, Zhang T, Scott A, Murray R, Sabourin L, Marti R, Topp E. 2017. Impact of dairy manure pre-application treatment on manure composition, soil dynamics of antibiotic resistance genes, and abundance of antibiotic-resistance genes on vegetables at harvest. Sci Total Environ. 581-582: 32-39.

Titilawo Y, Obi L, Okoh A. 2015. Antimicrobial resistance determinants of escherichia coli isolates 
recovered from some rivers in osun state, south-western nigeria: Implications for public health. Sci Total Environ. 523: 82-94.

UNEP. 2017. Antimicrobial resistance from environmental pollution among biggest emerging health threats, says UN Environment. https://www.unenvironment.org/news-and-stories/pressrelease/antimicrobial-resistance-environmental-pollution-among-biggest.

Vaz-Moreira I, Nunes O C, Manaia C M. 2014. Bacterial diversity and antibiotic resistance in water habitats: Searching the links with the human microbiome. FEMS Microbiol Rev. 38: 761-778.

Wang F H, Qiao M, Su J Q, Chen Z, Zhou X, Zhu Y G. 2014. High throughput profiling of antibiotic resistance genes in urban park soils with reclaimed water irrigation. Environ Sci Technol. 48: 9079-9085.

Wang F, Stedtfeld R D, Kim O S, Chai B, Yang L, Stedtfeld T M, Hong S G, Kim D, Lim H S, Hashsham S A, Tiedje J M, Sul W J. 2016. Influence of soil characteristics and proximity to antarctic research stations on abundance of antibiotic resistance genes in soils. Environ Sci Technol. 50: 12621-12629.

Wang F, Xu M, Stedtfeld R D, Sheng H, Fan J, Liu M, Chai B, de Carvalho T S, Li H, Li Z, Hashsham S A, Tiedje J M. 2018. Long-term effect of different fertilization and cropping systems on the soil antibiotic resistome. Environ Sci Technol. 52: 13037-13046.

Wang Q, Fish J A, Gilman M, Sun Y, Brown C T, Tiedje J M, Cole J R. 2015. Xander: Employing a novel method for efficient gene-targeted metagenomic assembly. Mbio. 3: 32-45.

Watts E J, Schreier J H, Lanska L, Hale S M. 2017. The rising tide of antimicrobial resistance in aquaculture: Sources, sinks and solutions. Mar Drugs. 15: 1-16.

WHO. 2017. WHO supports steps to develop the country's National Action Plan on Antimicrobial Resistance. https://afro.who.int/news/who-supports-steps-develop-countrys-national-actionplan-antimicrobial-resistance.

Xiong W, Sun Y, Ding X, Wang M, Zeng Z. 2015. Selective pressure of antibiotics on args and bacterial communities in manure-polluted freshwater-sediment microcosms. Front Microbiol. 
6: 194-194.

Yin X L, Jiang X T, Chai B L, Li L G, Yang Y, Cole J R, Tiedje J M, Zhang T. 2018. Args-oap v2.0 with an expanded sarg database and hidden markov models for enhancement characterization and quantification of antibiotic resistance genes in environmental metagenomes. Bioinformatics. 34: 2263-2270.

Zankari E, Hasman H, Cosentino S, Vestergaard M, Rasmussen S, Lund O, Aarestrup F M, Larsen M V. 2012. Identification of acquired antimicrobial resistance genes. J Antimicrob Chemoth. 67: $2640-2644$.

Zeng G, Wu H, Liang J, Guo S, Huang L, Xu P, Liu Y, Yuan Y, He X, He Y. 2015. Efficiency of biochar and compost (or composting) combined amendments for reducing $\mathrm{Cd}, \mathrm{Cu}, \mathrm{Zn}$ and $\mathrm{Pb}$ bioavailability, mobility and ecological risk in wetland soil. RSC Adv. 5: 34541-34548.

Zhang Y, Boyd S A, Teppen B J, Tiedje J M, Zhang W, Zhu D, Li H. 2018. Bioavailability of tetracycline to antibiotic resistant escherichia coli in water-clay systems. Environ Pollut. 243: 1078-1086.

Zhu Y G, Johnson T A, Su J Q, Qiao M, Guo G X, Stedtfeld R D, Hashsham S A, Tiedje J M. 2013. Diverse and abundant antibiotic resistance genes in chinese swine farms. P Natl Acad Sci USA. 110: $3435-3440$.

Zhu Y G, Zhao Y, Li B, Huang C L, Zhang S Y, Yu S, Chen Y S, Zhang T, Gillings M R, Su J Q. 2017. Continental-scale pollution of estuaries with antibiotic resistance genes. Nat Microbiol. 2: $16270-16277$. 


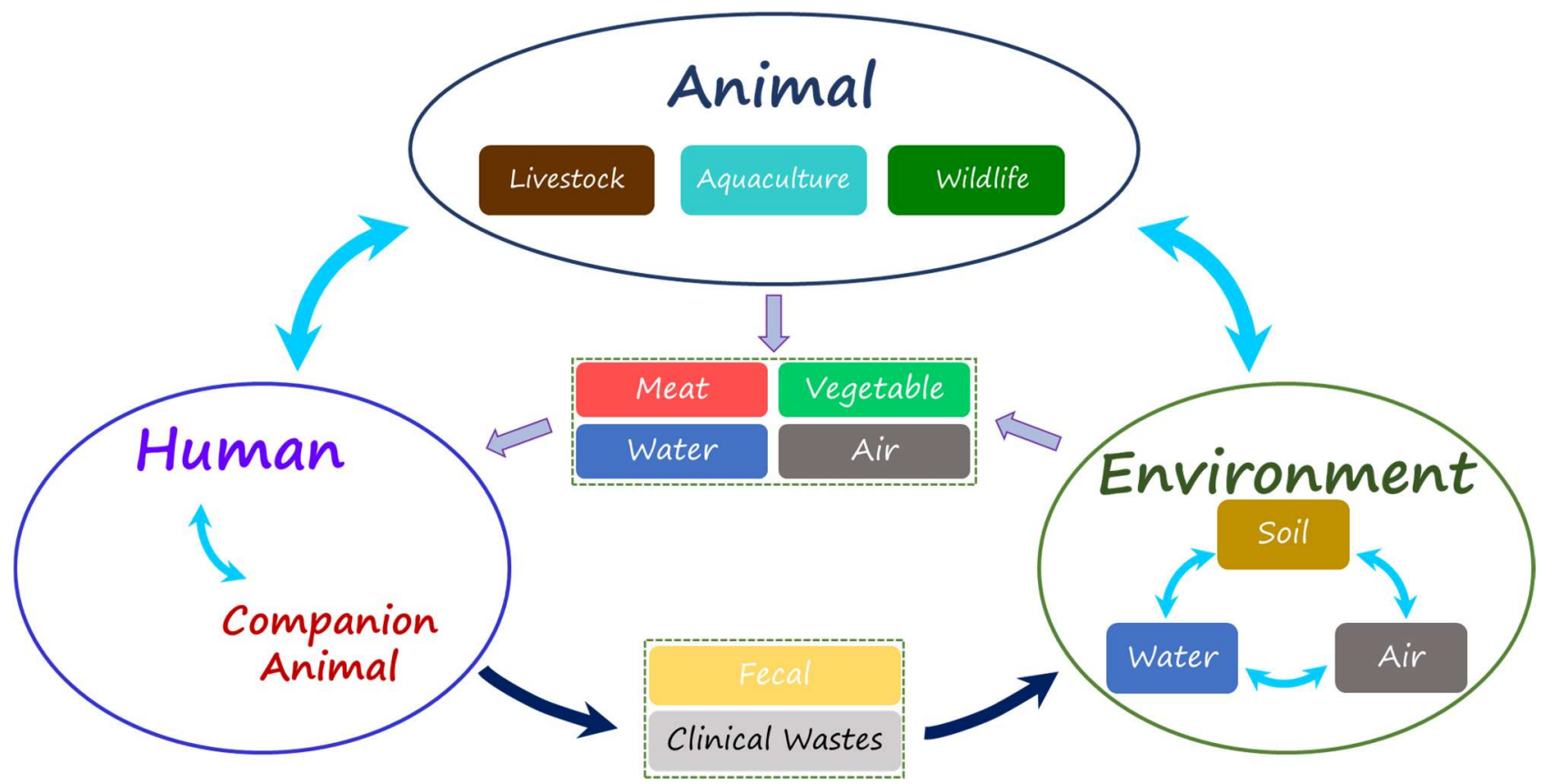

606 Fig. 1 The transmission of antibiotic resistance in the One Health framework with Human Health,

607 Animals and Environment as the major domains through which antibiotic resistance genes and 608 microbes reside, amplify and spread. Most arrows are in both directions reflecting these pathways, 609 and the cyclic nature of the problem. Human exposure can be directly from animals and from food, 610 water and air, but humans can also spread resistance to those domains, and especially via fecal wastes. 611 Companion animals are grouped with humans because of higher potential for ARG exposure and 612 bidirectional transfer. 